\title{
INFLUENCE OF RESIDUAL STRESS ON THE STABILITY OF STEEL COLUMNS AT ELEVATED TEMPERATURES
}

\author{
Andrei KERVALISHVILI, Ivar TALVIK \\ Tallinn University of Technology, Ehitajate tee 5, 19086 Tallinn, Estonia
}

Received 14 Jan 2015; accepted 13 May 2015

\begin{abstract}
Influence of residual stresses on the stability of steel columns with various sections at elevated temperatures has been studied. The potential effect of residual stresses on the stability of columns should be clarified, as the stability of compression elements in fire even without explicitly regarding residual stresses is not a straightforward phenomenon. Extensive numerical study was performed utilizing non-linear finite element method. Results for models ignoring and accounting for residual stresses were compared for different steel grades, various slenderness values, temperatures and section types. Results were compared with Eurocode method.
\end{abstract}

Keywords: column, buckling, Eurocode 3, elevated temperatures, numerical analysis, residual stresses.

\section{Introduction}

Resistance of steel columns is usually governed by global buckling. Buckling is a complex stability phenomenon, affected by several factors, including yield stress, geometrical imperfections, slenderness, section geometry, residual stresses and stress-strain relationship of steel. Stability of columns can be investigated by numerical or analytical models, which rely on certain simplified assumptions concerning several of the aforementioned factors. In order to evaluate the reliability of the analysis, the sensitivity of the models relative to those factors, like residual stress, need to be considered.

Residual stresses are present in steel sections in their unloaded state and these are among the factors that cannot be ignored, when evaluating the resistance of structural steel elements. Data on residual stresses in different section types and materials have been obtained in numerous experimental works. The distribution pattern and magnitude of residual stresses depend on the section topology and production technology. In hot rolled sections the residual stresses are mainly due to rolling process and uneven cooling, in cold-formed sections mainly due to cold bending during forming process and welding. The importance of residual stresses for stability was reported in the beginning of the 20-th century already and it has been extensively investigated (Galambos 1998). The influence of residual stresses on the stability of hot rolled and fabricated beams and columns at normal temperature has been thoroughly evaluated (Bild, Trahair 1989; Fuku- moto, Itoh 1980, 1981), the same in tubular columns has been also studied (Key et al. 1988; Landolfo, Mazzolani 1991; Sun, Packer 2014). The role of residual stresses on the behaviour of the whole structural system was evaluated by Shayan et al. (2014). In various works on column resistance at elevated temperatures the influence of residual stresses has been considered (Franssen et al. 1998; Talamona et al. 1997; Takagi, Deierlein 2007; Seif, McAllister 2013). Referring to reduction of residual stresses due to temperature some authors conclude, that residual stresses can be ignored in numerical models of columns (Yang et al. 2006).

The review of the publications above indicates that the information on the influence of residual stresses in fire conditions is not sufficient. Most of these studies have been focused at certain cases only regarding specific section types or limited parameter ranges and the influence of residual stresses is not the primary target of the works and a generalized review about the effect of residual stresses on buckling strength at elevated temperatures has not been provided.

The objective of the present paper is to obtain comprehensive information about the effect of residual stresses on steel columns at elevated temperatures. For this purpose a computational study is carried out on axially compressed columns with varying properties - steel grades and cross section types corresponding to different Eurocode buckling curves. Effects of residual stresses are examined for a wide range of temperatures and slen-

Corresponding author: Ivar Talvik

E-mail: ivar.talvik@ttu.ee 
derness values. The sensitivity of buckling resistance to the effect of residual stresses at elevated temperatures is evaluated for characteristic sets of parameters.

\section{Stability of steel columns at elevated temperatures}

Eurocode 3 (EN 1993-1-1 2005) provides a method for handling column stability at ambient temperatures in design practice. The proposed method uses Ayrton-Perry type model, slightly modified to calibrate against test results (Szalai, Papp 2010). The Eurocode model includes the influence of residual stresses combined with other imperfections by means of different buckling curves (EN 199311 2005). The present Eurocode method for axially loaded columns in fire (EN 1993-1-2 2004) is based on the comprehensive numerical (Talamona et al. 1997; Franssen et al. 1998) and experimental results. The proposed model has been derived on the basis of the model for ambient conditions, although due to modified material properties the phenomenon of stability in fire condition is more complex than in ambient conditions. The main reason for that is the stress-strain response of steel material - in ambient conditions using the idealized elastoplastic model with bilinear stress-strain relationship is justified, while in fire conditions model with elliptical region connecting two linear parts of the stress-strain curve should be used. Certain deviations of the present Eurocode 3 model from advanced numerical models for axially loaded steel columns in fire have been demonstrated. Researchers point out that at fire temperatures the proposed simplified models do not properly account for the nonlinear stress-strain relationship and bending stiffness (Knobloch et al. 2010). In some cases the results according to the Eurocode design expressions may be on the nonconservative side (Vila Real et al. 2004b). Similar to cold conditions the design method for the stability of axially loaded elements at elevated temperatures (EN 19931-2 2004) uses buckling curve approach to consider initial imperfections. Different from ambient temperatures only one buckling curve is applied for all sections, i.e. at elevated temperatures no distinction is made regarding fabrication process and section geometry.

\section{Residual stresses}

Residual stresses (RS) originate from the fabrication process of steel sections, depending on material, cross section type and manufacturing process. RS patterns of Eurocode 3 base documents (ECCS 1976, 1984) have been developed on the basis of extensive research of buckling of steel elements at ambient temperatures (Fig. 1).

Similar patterns are proposed for a large variety of combinations of complex phenomena, influencing RS. Most likely such unification of the simplified patterns may produce conservative results in many cases. Some recent studies point out the conservative character of the present RS models (Pasternak, Launert 2014) and underline the importance of providing more realistic approaches to the patterns of RS. As adequacy of simplified RS patterns is not the focus of this work the patterns of ECCS $(1976,1984)$ have been used in the present study in order to relate the results to the available data of previous works and the present Eurocode. The influence of RS on stability of steel elements in fire was described by Franssen (1993) and Vila Real et al. (2004a). Similar approach has been used in the present work. It has been demonstrated, that RS do not influence plastic capacity of a cross section, but the presence of the residual stresses makes the strains at reaching the fully plastic state higher compared to the specimen without residual stresses. The present work deals with symmetrical, first and second class sections (in terms of Eurocode), which represent quite a wide practical range.

\section{Bending stiffness at elevated temperatures}

The stiffness of a cross section (axial and/or bending) has major influence on the behaviour of a column. It can be shown, that stiffness in fire conditions depends on stress state, temperature and load level and the response of the stiffness to the changes of those parameters is highly nonlinear. Regarding the symmetry of the residual stress distribution and assuming that residual stresses do not alter the section's plastic capacity, the residual stresses can influence the column behavior only by changing the bending stiffness of the section.
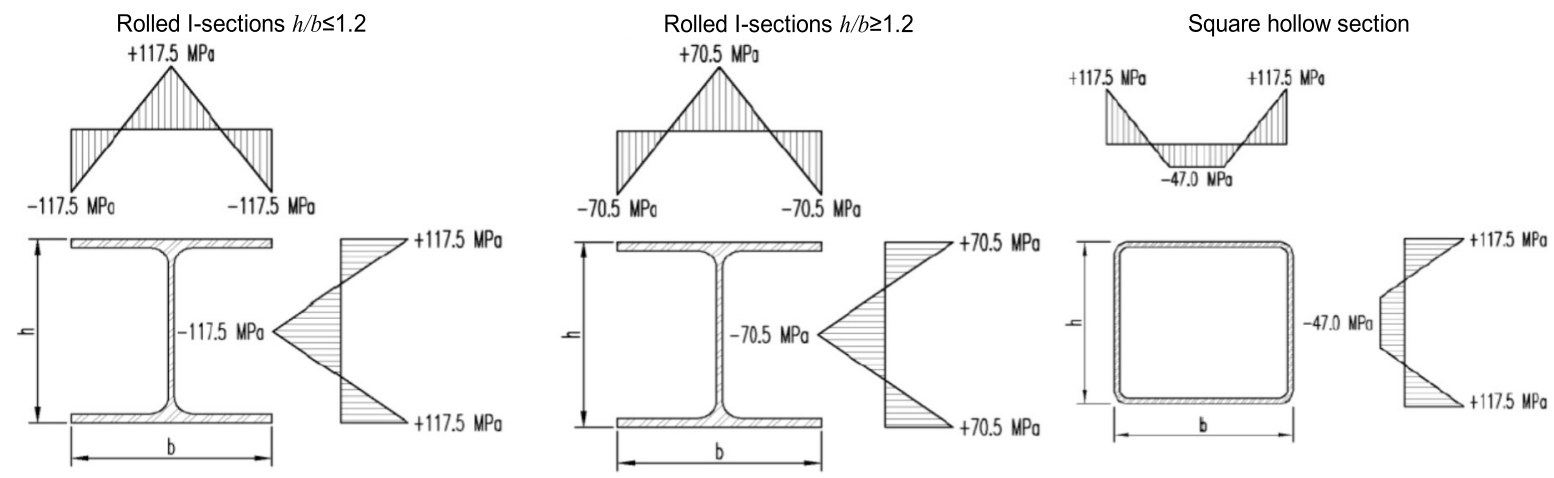

Fig. 1. Residual stress distribution patterns (“-" stands for compression; "+” stands for tension) 

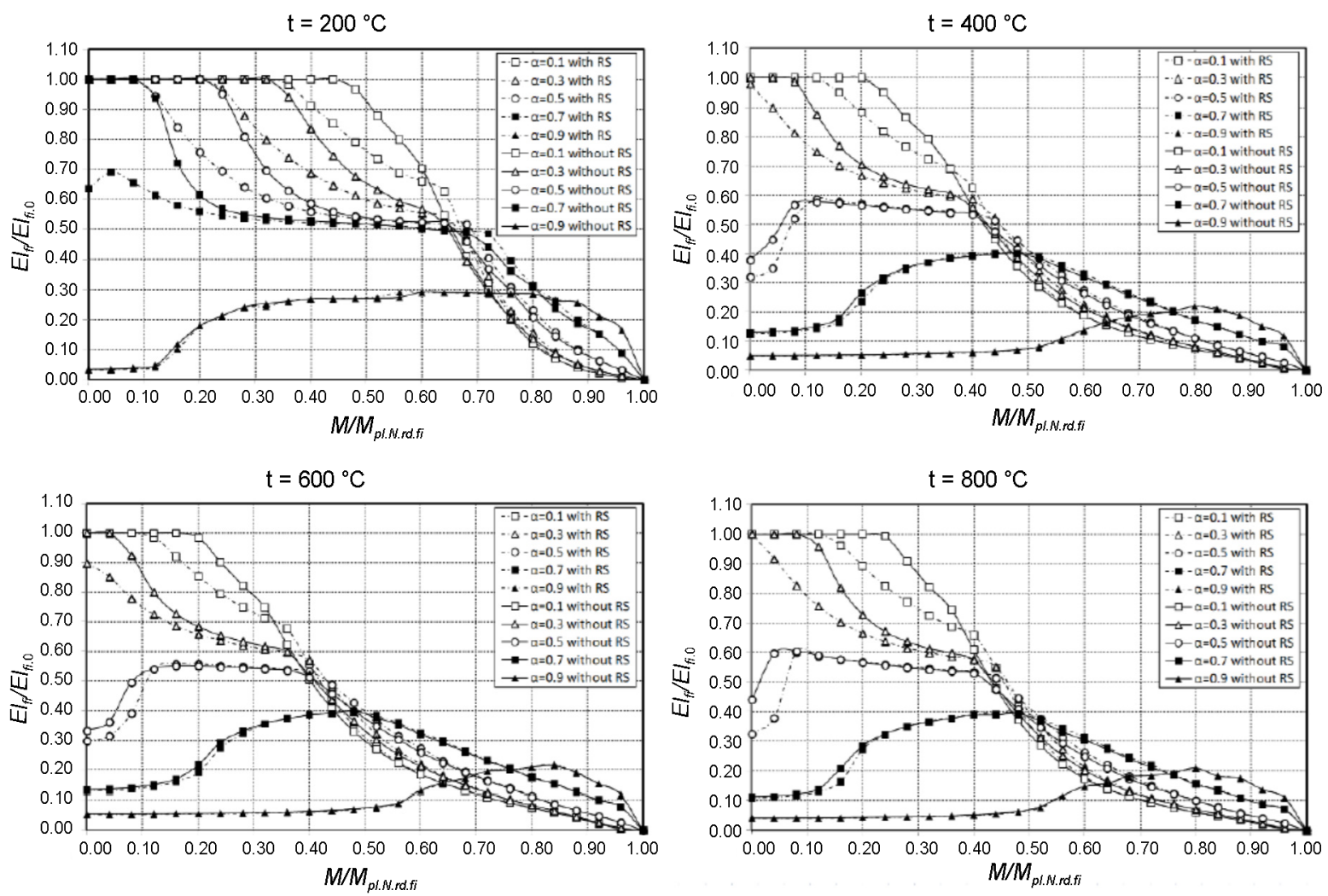

Fig. 2. Influence of RS on the stiffness reduction factor $\left(E I_{f i} / E I_{f i .0}\right)$ as a function of the bending capacity utilization factor $\left(M / M_{\text {pl.N.Rd.fi }}\right)$ for rolled I-section (HEA500) strong axis

Extensive numerical study on the influence of residual stresses on the bending stiffness in different temperature modes and stress states has been carried out. The results for section HEA500 at 4 temperature ranges are presented in Figure 2. $E I_{f i}$ stands for the bending stiffness in fire accounting for the dependence of material properties on temperature and stress state, $E I_{f i .0}$ is the bending stiffness in fire accounting for the dependence of material properties only on temperature (zero stress state), $M$ is the acting bending moment, $M_{p l . N . r . f . f}$ is the bending moment capacity in fire situation at certain axial load level. Two sets of curves are presented in each diagram: the continuous line corresponds to the bending stiffness without RS and the dash-dotted line corresponds to the bending stiffness with RS. The different curves correspond to different axial load levels - factor $\alpha=N / N_{p l . R d . f}$, where $N$ is the acting axial load and $N_{p l . R d . f i}$ is the axial load capacity in fire situation. Although depending on temperature and the utilization factor, the impact of RS on the bending stiffness has quite diverse character, some general features can be specified from Figure 2:

- bending stiffness dependence on stress state is complex even without residual stresses and is defined by material law;

- higher axial load levels (higher $\alpha$-factor values) decrease the influence of RS on bending stiffness;

- higher $M / M_{\text {pl.N.r.f.fi }}$ factor values (higher curvatures) decrease the influence of RS on bending stiffness.
It has been shown that RS have certain influence on the bending stiffness and consequently on the buckling resistance of the column. The impact of the residual stresses varies in a complex manner depending on the section type, load level, temperature and curvature. In order to illustrate and understand better the effect of residual stresses on the buckling capacity of the columns, corresponding simulations were carried out and results are presented in the following section.

\section{Numerical model of columns}

Buckling capacities of compression elements were calculated by finite element method, using 4-node shell type finite strain elements with 5 through thickness integration points in software package ANSYS (element SHELL 181), regarding geometrical and material nonlinearities. The model and element type are the same as validated by Zhang et al. (2013). Mesh size was chosen as flange width / 20. Temperature field with uniform through thickness and through length distribution was applied, which is adequate for unprotected steel profiles. Initial deformed shape was acquired by performing linear buckling analysis. Deformed shape was scaled in order for the maximum initial deformation in the middle to become $L$ / 1000. Residual stresses were introduced according to the patterns in Figure 1. Residual stresses were introduced as initial stresses at normal temperature. Static analysis step 
with temperature variation from normal to the one under consideration was performed as described by Franssen (1996). This step is important, as in reality we deal with residual strains and it would be wrong to apply residual stress patterns presented in Figure 1 into the model with mechanical properties (stress-strain relationships) corresponding to the elevated temperature conditions. Material models of Eurocode 3 were applied. Calculation cycle can be summarized using the following steps:

- Step 1: linear buckling to acquire the initial deformed shape;

- Step 2: initial stress introduction;

- Step 3: temperature variation;

- Step 4: limit loading.

Finite element method has become a standard procedure for dealing with structural problems like steel structures in fire conditions (Talamona et al. 1997; Franssen et al. 1998; Vila Real et al. 2004b; Knobloch et al. 2010; Pauli 2013), but numerical models must be validated against test results. The finite element model of the present work was validated against the data from experiments by Franssen et al. (1998). Validation was performed on the basis of 21 cases with various sections, slenderness ratios and steel grades. Failure temperatures achieved during testing and calculations were compared. Results of the validation are presented in Figure 3. Validation results are in accordance with those reported by other researchers (Talamona et al. 1997; Franssen et al. 1998; Vila Real et al. 2004a, 2004b; Somaini et al. 2012; Pauli 2013).

The modelling program is summarized in Table 1.

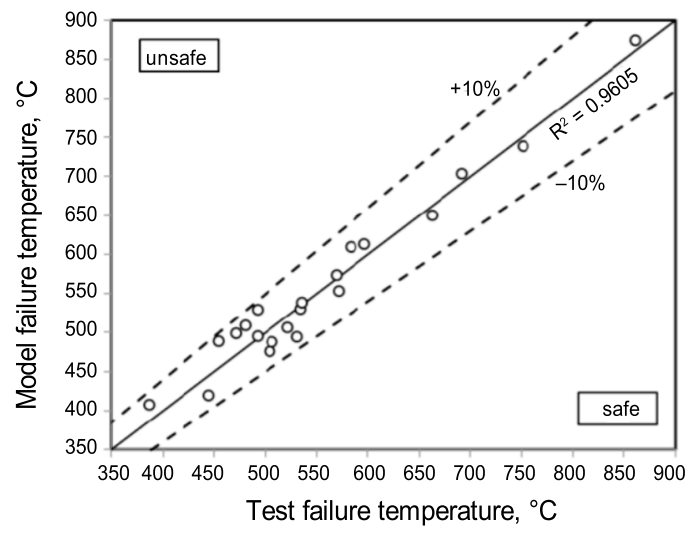

Fig. 3. Validation of the numerical model against test results (Franssen et al. 1998)
Sections have been selected to represent Eurocode 3 buckling curves (EN 1993-1-1 2005). Thirteen slenderness values $\left(\bar{\lambda}_{20}=0.3 \ldots 2.0\right)$ were selected to model in 8 temperature ranges. The total number of models was $260+260$ (without residual stresses + with residual stresses). Results for certain temperatures are presented in the form of buckling factors $\chi$ in Figure 4 and Figure 5 for steel grades S235 and S355, respectively.

In the figures for each temperature results for buckling factor without residual stresses are presented in the left side top diagram, results for buckling factor with residual stresses are presented in the left side bottom diagram and results for those two are compared in the right side diagram. Results of numerical studies (Figs 4 and 5) are summarized as follows:

- the influence of residual stresses depends on steel grade (due to the different yield stress limit). This is evident, as residual stress pattern is invariant to steel grade and relation between the maximum;

- the influence of residual stresses depends on temperature;

- two groups of curves can be distinguished in the situation, where residual stresses are not considered. Residual stresses magnify this separation. The first group includes rectangular hollow sections and strong axis buckling of hot-rolled I-sections. The second group includes weak axis buckling of I-sections;

- for the first group of sections, within certain slenderness range, the presence of residual stresses increases the buckling capacity. For all temperatures, this region starts with minimum slenderness values around $\bar{\lambda}_{20}=0.4$ and before $\bar{\lambda}_{20}=1.0$ depending on the temperature. Increase of buckling capacity is still quite low, remaining below $2.5 \%$;

- for the second group of sections, residual stresses decrease the buckling capacity for all slenderness values;

- for both groups, residual stresses have stronger influence on elements with higher slenderness, achieving the maximum values within the range $\bar{\lambda}_{20}=1.3 \ldots 1.5$. Results of Figs 4 and 5 are summarized also in Table 2 in the form of indicative impact factors, illustrating the effect of residual stresses for all temperature ranges and for two steel grades.

Two factor values are presented in format $\alpha_{1} / \alpha_{2}$, where $\alpha_{1}$ corresponds to the section type 1 (rolled

Table 1. Modelling scheme

\begin{tabular}{|c|c|c|}
\hline Description & Profiles & Steel \\
\hline Hot rolled I-sections $h \backslash b \leq 1.2-$ strong axis & HEA120, HEB300 & $\mathrm{S} 235, \mathrm{~S} 355$ \\
\hline Hot rolled I-sections $h \backslash b \leq 1.2-$ weak axis & HEA120, HEB300 & $\mathrm{S} 235, \mathrm{~S} 355$ \\
\hline Hot rolled I-sections $h \backslash b \geq 1.2-$ strong axis & HEA500, HEB 800 & $\mathrm{~S} 235, \mathrm{~S} 355$ \\
\hline Hot rolled I-sections $h \backslash b \geq 1.2$ - weak axis & HEA500, HEB 800 & $\mathrm{~S} 235, \mathrm{~S} 355$ \\
\hline Square hollow sections & RHS $100 \times 100 \times 5.0$, RHS $300 \times 300 \times 8.0$ & $\mathrm{~S} 235, \mathrm{~S} 355$ \\
\hline
\end{tabular}



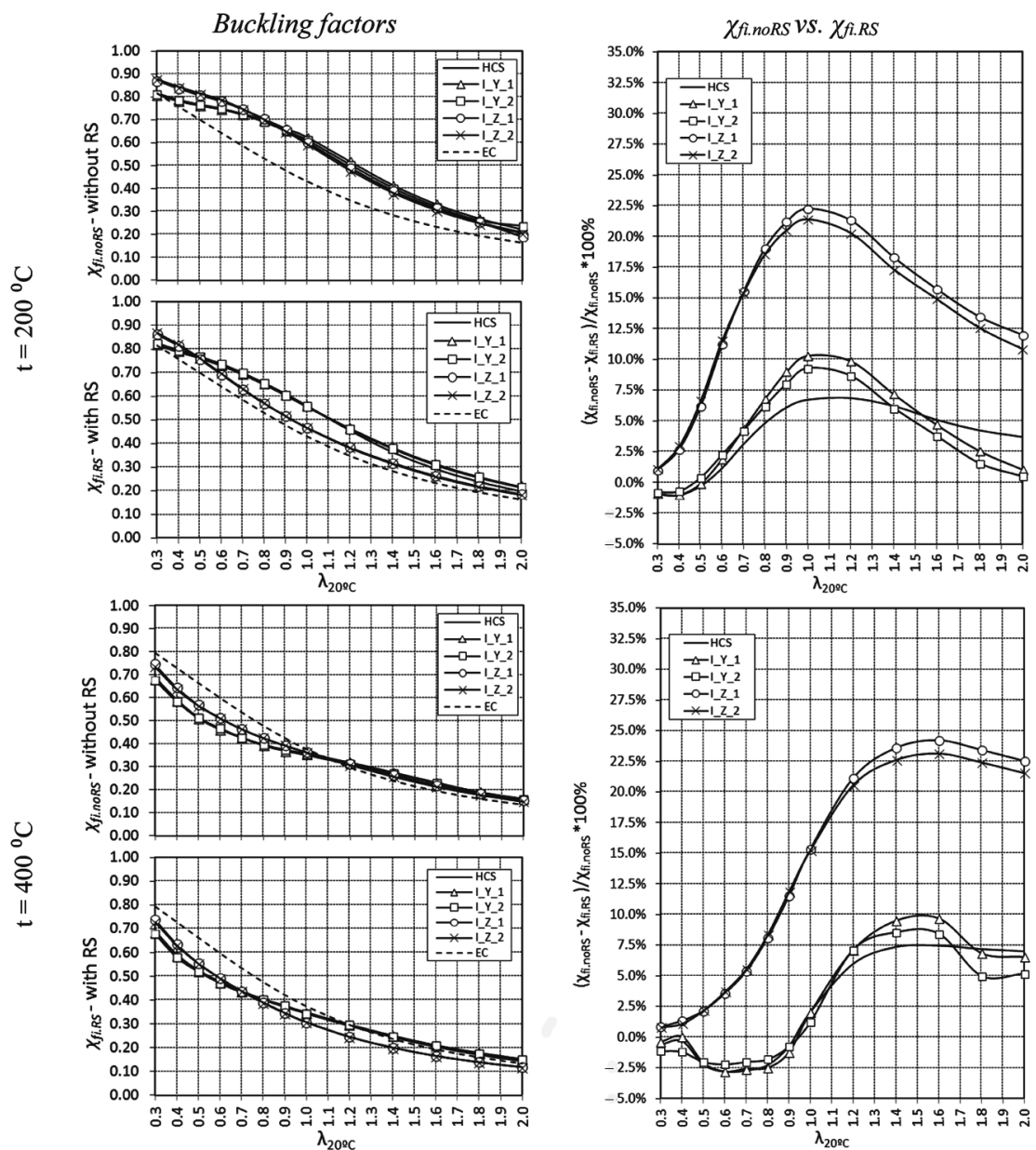

递兽:

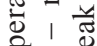

萡 $n_{1}$

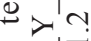

责

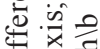

要

훙

a क ष

$\simeq$ 논

亭 $v 1 \frac{0}{0}$

3기

$\exists \mathscr{g}^{2}$

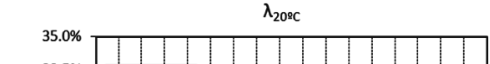

然

s.

的元

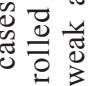

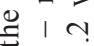

के IV|

든

을

की

글 응

0 is

的范 卷

तิ 3

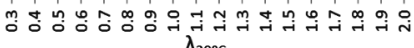

$\lambda_{20 \mathrm{CO}}$
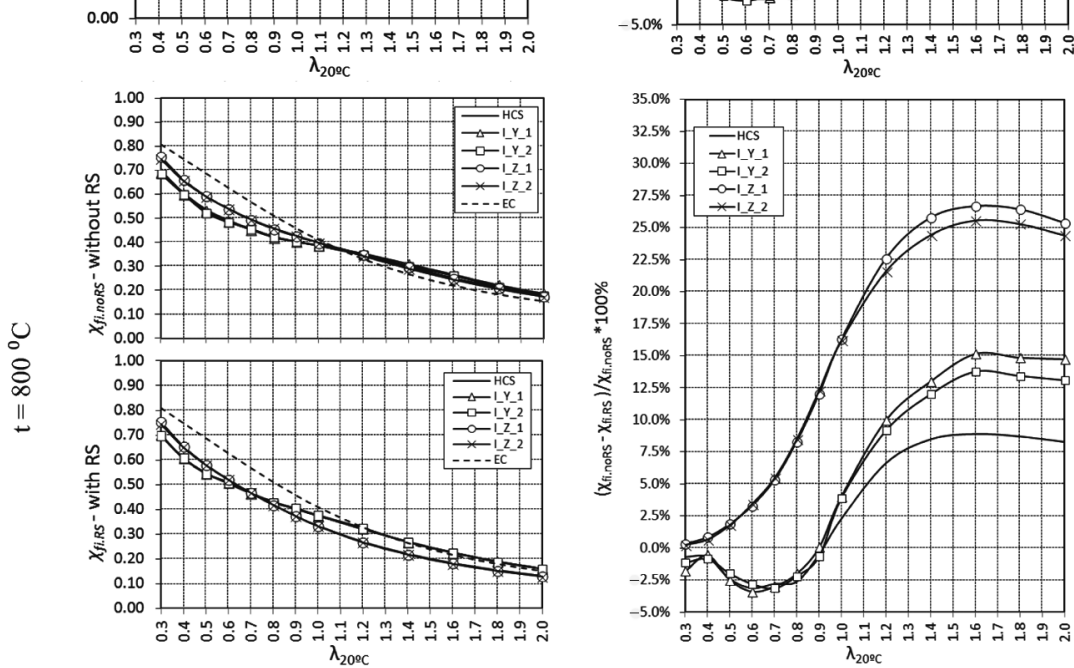

으 1

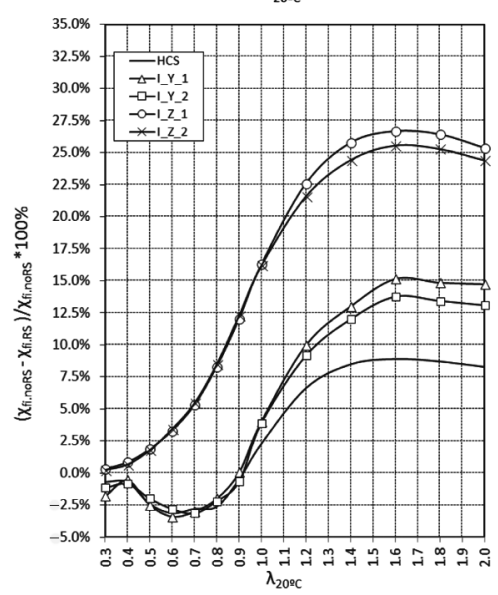

颉

造包的

क्ष

究总

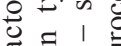

馬.

bo 0

要边

可衰:

$\emptyset$ एँ

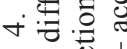

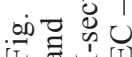



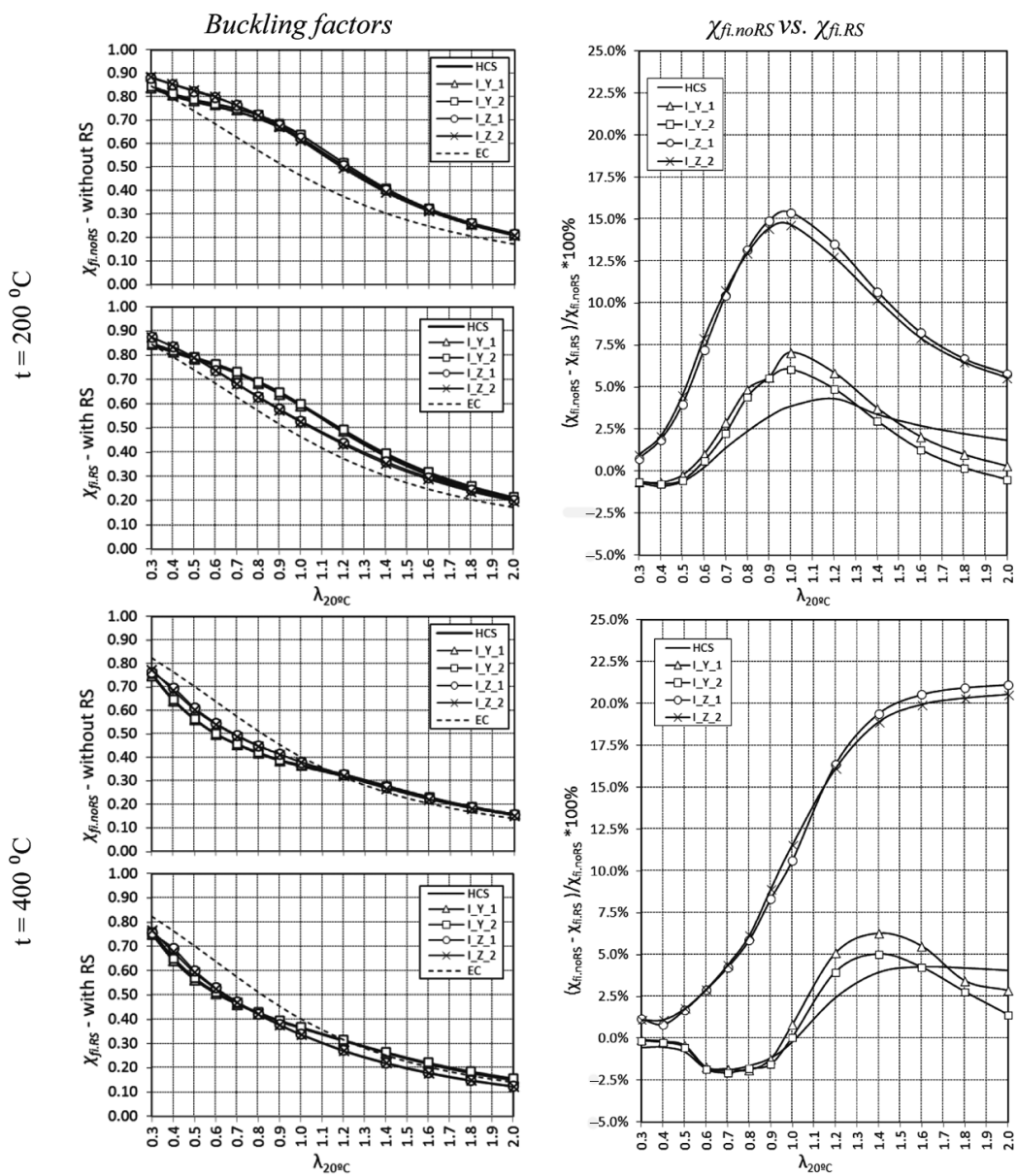

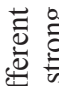

$\Psi_{1} \infty$

至

s.

至至空

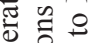

을일

Ф.

氙 总

巴잉

1

के $v_{1}$

थ $>$.
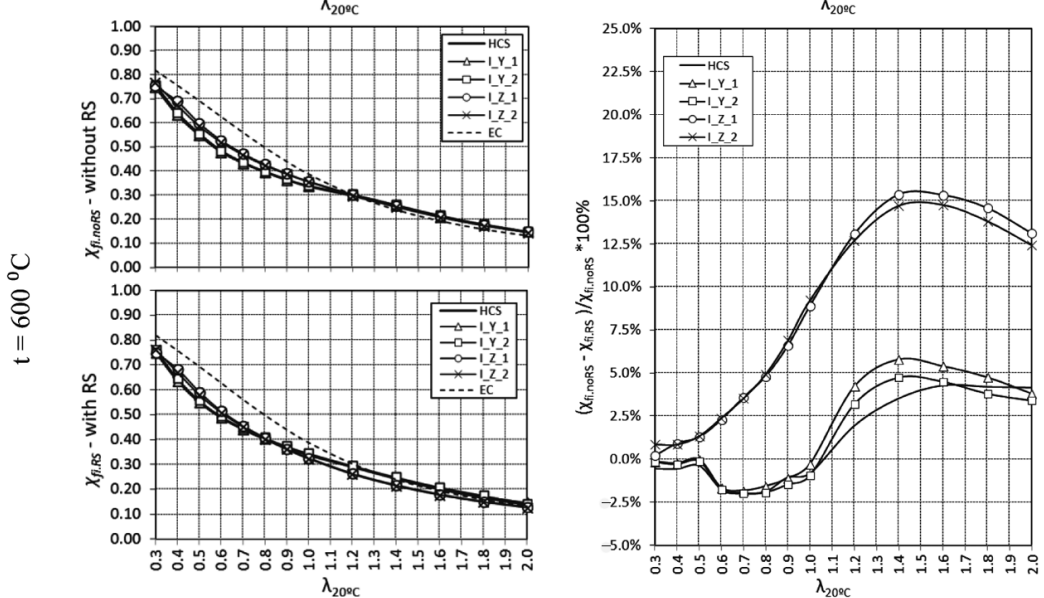

言管

인?

을

도으

VI

包是

ช 4

을 궁

¿

듕

吾 N

뭉

$0-1 \cdot \frac{\omega}{x}$

in

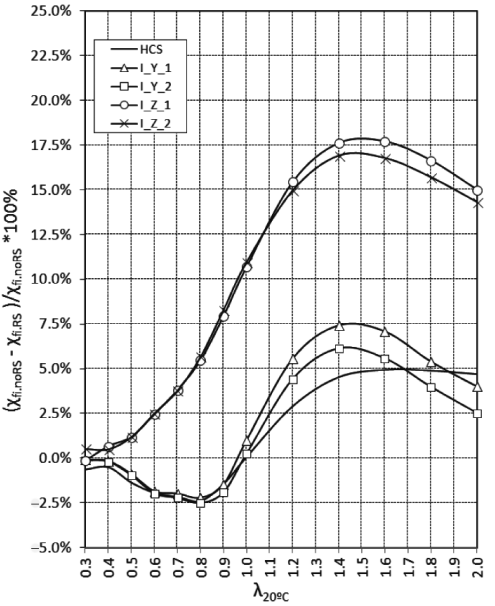

थิ ถู

윰ำ

పू

ष

흥으음

응요

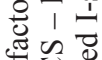

일을

竞品-

的昰 


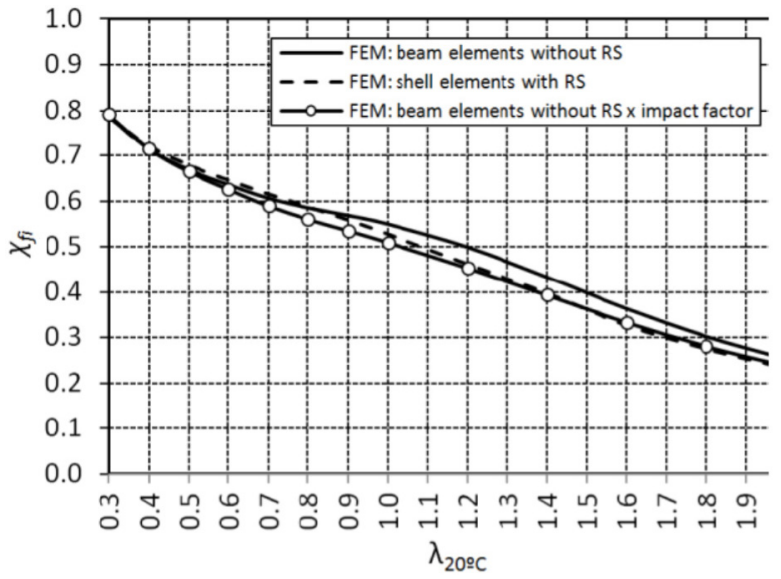

Fig. 6. Buckling factors for models with residual stresses, without residual stresses and models adjusted with impact factor (HEA500, $\mathrm{t}=900{ }^{\circ} \mathrm{C}, \mathrm{S} 355$, strong axis)

I-sections strong axis and square hollow sections) and $\alpha_{2}$ corresponds to the section type 2 (rolled I-sections weak axis). The impact factors are also presented in analytical form for both types of sections:

$$
\begin{aligned}
& \gamma_{\text {imp } .1}=\frac{0.9957 \lambda_{20^{\circ} \mathrm{C}}^{2}-2.068 \lambda_{20^{\circ} \mathrm{C}}+1.443}{\lambda_{20^{\circ} \mathrm{C}}^{2}-2.024 \lambda_{20^{\circ} \mathrm{C}}+1.424} ; \\
& \gamma_{\text {imp } .2}=\frac{0.8094 \lambda_{20^{\circ} \mathrm{C}}^{2}-0.7791 \lambda_{20^{\circ} \mathrm{C}}+0.5301}{\lambda_{20^{\circ} \mathrm{C}}^{2}-0.871 \lambda_{20^{\circ} \mathrm{C}}+0.5455},
\end{aligned}
$$

where: $\gamma_{i m p .1}$ is the impact factor for section type 1 and $\gamma_{i m p .2}$ for section type 2 respectively;,$\lambda_{20 C}$ is the reduced slenderness of the column at ambient temperatures.

In general, structural elements can be modelled at different levels of complexity in order to achieve the balance between resources, time and expected accuracy. For example, columns in FEM applications can be modelled by beam elements or shell elements. Implementing residual stresses in any kind of FEM based model as initial strain is a specific task, which needs attention and time. It is not convenient or possible to apply initial strain in less advanced FEM applications. The presented impact factors enable indirectly take account of the residual stresses by simple multiplication of the results obtained in less advanced models by the appropriate impact factor from Eqn (1) or approximately from Table 2. As an example the results of this kind of approach are presented in Figure 6 for a column with section HEA500. Buckling factor for a finite beam element model without residual stresses is shown by a solid line. Those values have been multiplied by appropriate impact factors. The resulting values compare well to the relevant results of a full finite shell element model with residual stresses.
Table 2. Impact indicators of the influence of residual stresses

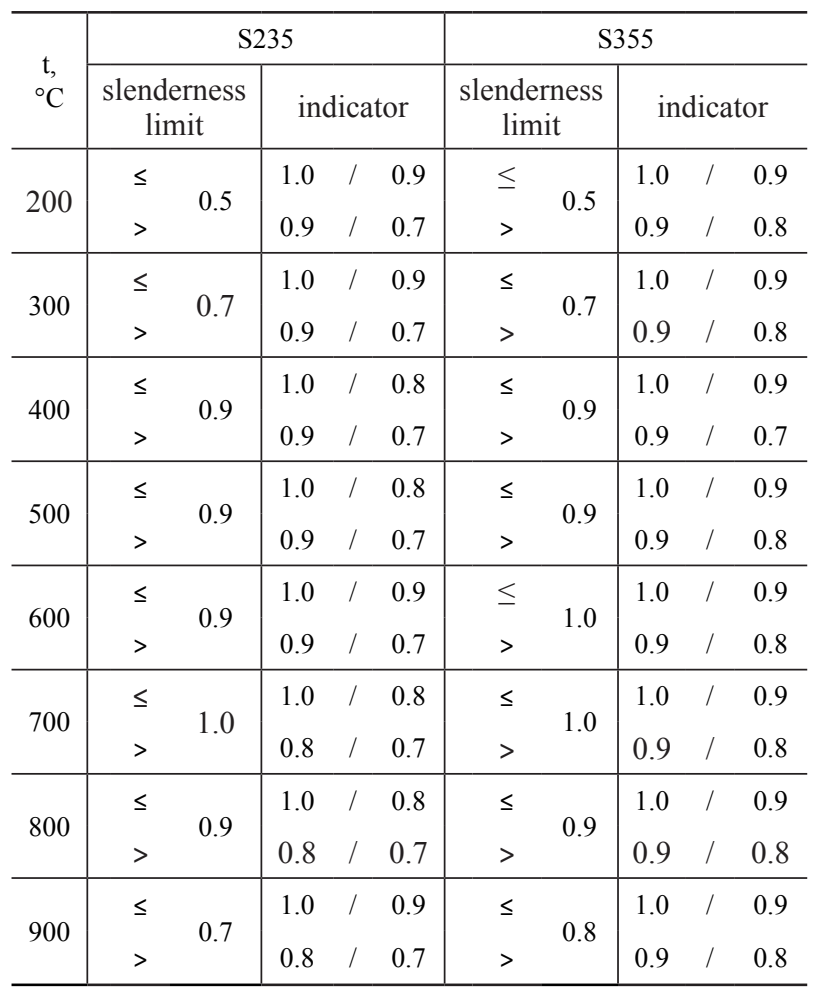

\section{Conclusions}

This paper has presented the results of a comprehensive numerical study, enabling to evaluate the effect of residual stresses on the buckling capacity of axially loaded columns at elevated temperatures. Characteristic types of sections according to Eurocode 3 buckling curves have been studied by FEM simulations in a wide range of temperatures. The generated data indicate that the influence of residual stresses is diverse and deserves detailed consideration to avoid oversimplification. The results reaffirm that the effect of residual stresses is negligible in certain lower range of slenderness for strong axis buckling of hot-rolled H-sections and hollow section elements. Strong axis buckling out of this range and weak axis buckling of $\mathrm{H}$-sections is more sensitive to the influence of residual stresses and disregarding them brings about reduction of accuracy. Independent of the residual stresses the design code prediction of the buckling capacity for certain lower slenderness range at fire temperatures appear on the unconservative side compared to the numerical model. The results of the present study can be used for indicative evaluation of the sensitivity of numerical and analytical models to residual stresses, modification of simplified models and interpretation of experimental data.

\section{References}

Bild, S.; Trahair, N. S. 1989. In-plane strengths of steel columns and beam columns, Journal of Constructional Steel Research 13(1): 1-22.

http://dx.doi.org/10.1016/0143-974X(89)90002-3 
ECCS. 1984. European convention for constructional steelwork. $1^{\text {st }}$ ed. Technical Committee 8 - Structural Stability. Technical Working Group 8.2. Ultimate Limit State Calculation of Sway Frames with Rigid Joints.

ECCS. 1976. European convention for constructional steelwork. $2^{\text {nd }}$ ed. Technical Committee 8 - Structural Stability. Manual on Stability of Steel Structures.

EN 1993-1-1. Design of steel structures - Part 1-1: General rules and rules for buildings. CEN, Brusells, 2005. $102 \mathrm{p}$.

EN 1993-1-2. Design of steel Structures - Part 1-2: General rules - structural fire design. CEN, Brusells, 2004. $81 \mathrm{p}$.

Franssen, J. M.; Talamona, D.; Kruppa, J; Cajot, L. G. 1998. Stability of steel columns in fire: Experimental evaluation, Journal of Structural Engineering 124(2): 158-163.

http://dx.doi.org/10.1061/(ASCE)0733-9445(1998)124:2(158)

Franssen, J. M. 1993. Residual stresses in steel profiles submitted to the fire: an analogy, in Proceedings of the $3^{\text {rd }}$ CIB/W14 FSF Workshop on Modelling, 25-26 January 1993, Rijswijk, the Netherlands, 103-112.

Fukumoto, Y.; Itoh, Y. 1980. Strength variation of laterally unsupported beams, Journal of the Structural Division 106(1): 165-181.

Fukumoto, Y.; Itoh, Y. 1981. Statistical study of experiments on welded beams, Journal of the Structural Division 107(1): 89-103.

Galambos, T. V. 1998. Guide to stability design criteria for metal structures. New York: John Wiley \& Sons. 911 p.

Key, P. W.; Hasan, S. W.; Hancock, G. J. 1988. Column behaviour of cold-formed hollow sections, Journal of Structural Engineering 114(2): 390-407.

http://dx.doi.org/10.1061/(ASCE)0733-9445(1988)114:2(390)

Knobloch, M.; Somaini, D.; Pauli, J.; Fontana, M. 2010. Stability of steel columns in fire, in Proceedings of the International Colloquium "Stability and Ductility of Steel Structures" (SDSS'Rio 2010), 8-10 September 2010, Rio de Janeiro, Brazil, 465-472.

Landolfo, R.; Mazzolani, F. M. 1991. The influence of the variation through the thickness of residual stresses in tubular columns, Journal of Constructional Steel Research 19(1): 49-57. http://dx.doi.org/10.1016/0143-974X(91)90063-7

Pasternak, H.; Launert, B. 2014. Improved design approaches for the load bearing capacity of welded I-profiles from high strength steel considering realistic residual stresses, in The $7^{\text {th }}$ European Conference on Steel and Composite Structures, Eurosteel 2014, 10-12 September 2014, Naples, Italy, 159-160.

Pauli, J. C. 2013. The behaviour of steel columns in fire: $\mathrm{PhD}$ thesis. ETH Zürich, Germany.
Seif, M.; McAllister, T. 2013. Stability of wide flange structural steel columns at elevated temperatures, Journal of Constructional Steel Research 84: 17-26. http://dx.doi.org/10.1016/j.jcsr.2013.02.002

Shayan, S.; Rasmussen, K. J. R.; Zhang, H. 2014. Probabilistic modelling of residual stress in advanced analysis of steel structures, Journal of Constructional Steel Research 101: 407-414. http://dx.doi.org/10.1016/j.jcsr.2014.05.028

Somaini, D.; Knobloch, M.; Fontana, M. 2012. Buckling of steel columns in fire: non-linear behaviour and design proposal, Steel Construction 5: 175-182. http://dx.doi.org/10.1002/stco.201210022

Sun, M.; Packer, J. A. 2014. Direct-formed and continuousformed rectangular hollow sections - comparison of static properties, Journal of Constructional Steel Research 92: 67-78. http://dx.doi.org/10.1016/j.jcsr.2013.09.013

Szalai, J.; Papp, F. 2010. On the theoretical background of the generalization of Ayrton-Perry type resistance formulas, Journal of Constructional Steel Research 66(5): 670-679. http://dx.doi.org/10.1016/j.jcsr.2009.12.013

Takagi, J.; Deierlein, G. G. 2007. Strength design criteria for steel members at elevated temperatures, Journal of Constructional Steel Research 63(8): 1036-1050. http://dx.doi.org/10.1016/j.jcsr.2006.10.005

Talamona, D.; Franssen, J. M.; Schleich, J. B.; Kruppa, J. 1997. Stability of steel columns in case of fire: numerical modeling, Journal of Structural Engineering 123(6): 713-720.

http://dx.doi.org/10.1061/(ASCE)0733-9445(1997)123:6(713)

Vila Real, P. M. M.; Cazeli, R.; Simoes da Silva, L.; Santiago, A.; Piloto, P. 2004a. The effect of residual stresses in the lateral-torsional buckling of steel I-beams at elevated temperature, Journal of Constructional Steel Research 60(3-5): 783-793. http://dx.doi.org/10.1016/S0143-974X(03)00143-3

Vila Real, P. M. M.; Lopes, N.; Simoes da Silva, L.; Piloto, P.; Franssen, J. M. 2004b. Numerical modelling of steel beam-columns in case of fire - comparison with Eurocode 3, Fire Safety Journal 39(1): 23-39. http://dx.doi.org/10.1016/j.firesaf.2003.07.002

Yang, K.; Lee, H.; Chan, O. 2006. Experimental study of fire-resistant steel H-columns at elevated temperatures, Journal of Constructional Steel Research 62(6): 544-553. http://dx.doi.org/10.1016/j.jcsr.2005.09.008

Zhang, C.; Gross, J. L.; McAllister, T. P. 2013. Lateral torsional buckling of steel W-beams subjected to localized fires, Journal of Constructional Steel Research 88: 330-338. http://dx.doi.org/10.1016/j.jcsr.2013.06.004

Andrei KERVALISHVILI. PhD student at the Department of Structural Design, Tallinn University of Technology, Estonia. Research interests: steel structures, structures in fire, numerical methods.

Ivar TALVIK. Associate Professor at the Department of Structural Design, Tallinn University of Technology, Estonia. Research interests: steel structures, structures in fire. 